\title{
Comparison of MTF Measurement Methods in CT Images for Various Reconstruction Kernels
}

\author{
Fakhri Ramadhani Arisyi, Choirul Anam, Catur Edi Widodo \\ Department of Physics, Faculty of Sciences and Mathematics, Diponegoro University, Jl. Prof. Soedarto SH, \\ Tembalang, Semarang 50275, Central Java, Indonesia
}

\section{Article Info \\ Volume 8, Issue 3 \\ Page Number : 396-405}

\section{Publication Issue}

May-June-2021

\section{Article History}

Accepted : 20 May 2021

Published : 30 May 2021

\begin{abstract}
This study aimed to compare several methods of measuring the modulation transfer function (MTF) for different reconstruction kernels, using a point phantom, a small-circular (S-circular) Teflon object, and the automated edge of a PMMA phantom. The copper wire section of a phantom was used for the point method. The small-circular (S-circular) teflon object within the HU linearity section was used for measuring MTF using ImQuest software. The automated edge of a PMMA phantom was used to automatically measure the MTF. The three methods were implemented in images reconstructed with ten different kernels. It was found that the three methods produced comparable MTFs for all the kernels used. However, the automated edge of the PMMA phantom produced slightly smaller spatial resolutions compared with the two other methods. The differences between the automated edge of PMMA and the point method were small, i.e. $0.04 \mathrm{cycle} / \mathrm{mm}$ for both 10\% MTF and 50\% MTF. The differences between the automated edge of PMMA and the S-circular phantom were 0.05 cycle $/ \mathrm{mm}$ and 0.03 cycle $/ \mathrm{mm}$ for $10 \%$ MTF and 50\% MTF. We found that the "UA" kernel produced the lowest spatial resolution values of $0.32,0.33$, and $0.31 \mathrm{cycle} / \mathrm{mm}$ of $50 \% \mathrm{MTF}$ for point, Scircular object, and automated edge PMMA, respectively. The "YD" produced the highest spatial resolution values of $0.78,0.76$, and $0.67 \mathrm{cycle} / \mathrm{mm}$ of $10 \%$ MTF for point, S-circular object, and automated edge PMMA, respectively. We successfully compared three methods of MTF measurement. The three methods produce comparable MTFs, so that each method can be used for accurately measuring MTF depending on phantom and software available in the CT center.
\end{abstract}

Keywords: Spatial Resolution, Modulation Transfer Function, Reconstruction Kernel, Edge of PMMA, Point Phantom, ImQuest Software

\section{INTRODUCTION}

Computed tomography (CT) uses high-energy X-ray beams to generate images with high contrast and spatial resolution $[1,2]$. The images represent a linear attenuation map within the body [3]. Several reconstruction kernels have been widely implemented in CT scanners in order to obtain quality images depending on the type of examination. With a reconstruction kernel, a CT scanner is 
expected to produce readable images of the patient for accurate diagnosis at the lowest possible dose $[4,5]$. Several types of kernels have been developed, each with specific characteristics [6, 7]. The sharp kernel produces images with high noise and high spatial resolution [8], while the smooth kernel produces images with low noise and low spatial resolution [9].

Several parameters are used for quantifying good image quality, including noise, low-contrast discrimination, and spatial resolution $[10,11]$. Spatial resolution is a measure of how accurately two adjacent small objects in the image can be discriminated, since an image is blurred by the CT system. The spatial resolution is affected by many parameters, including field of view (FOV) [12], reconstruction kernel [13], slice thickness [14], and magnification [15]. Quantitative calculations of spatial resolution for CT scanners often use a point object [16, 17], line object [18], or edge object each with its own spread function, namely the point spread function (PSF), the line spread function (LSF) and the edge spread function (ESF) [19]. These spread functions are used to calculate the spatial resolution in terms of modulation transfer function (MTF) [19, 20].

The methods for MTF calculation are continuously being refined in order to get accurate, precise, and effective results. Several studies used the point object method for MTF calculation [21-24]. An extended of an automated algorithm for MTF calculation using a point object method developed $[16,25]$. The algorithm performs a calculation of MTF by automatically determining the ROI [25]. Compared with the standard fitting method, the 50\% MTF difference for $1.1 \mathrm{~mm}$ and $1.7 \mathrm{~mm}$ focal spot were $2.8 \%$ and 2.4\%, respectively [25]. The American Association of Physicist in Medicine (AAPM) developed software to calculate the MTF, called ImQuest [26], which uses several circular ROIs utilized for testing Hounsfield unit (HU) linearity. Several studies have evaluated the ImQuest software
[27-29]. Recently, Anam et al. [30] developed an algorithm for automatic MTF measurements using an edge of the polymethyl methacrylate (PMMA) phantom, which was rotated by about 45 degrees to avoid the holes within the phantom. This method was validated by comparison with the standard fitting method and point object methods, and gave MTF 50\% within $\pm 2 \%$ and $\pm 4 \%$ respectively for various FOVs [30]. Subsequently, the algorithm was improved to handle inhomogeneity in the phantom. Hak et al. [31] extended the software to remove the holes within the PMMA phantom so that it could be used regardless of the angle of the phantom.

However, these methods have not been compared on a single CT scanner for various reconstruction kernels. The purpose of this study was to compare the three methods of MTF measurements, i.e. point method, small-circular object method by ImQuest, and edge of PMMA phantom, for various reconstruction kernels..

\section{METHODS AND MATERIAL}

\section{A. Phantom and CT scanner}

Two different types of phantoms were used. The first was a Philips Medical Systems Brilliance 16 series performance phantom [32], and the second was a head PMMA phantom with a diameter of $16 \mathrm{~cm}$ and length of $20 \mathrm{~cm}[33,34]$.

The Philips phantom was placed in the phantom holder provided by the vendor. For MTF measurement with the point object method, the "spatial resolution" part of the phantom, a copper wire of diameter $0.18 \mathrm{~mm}$, was scanned. MTF measurement using the ImQuest software utilized a small-circular (S-circular) piece of the teflon object within "HU linearity" part of the phantom. The PMMA phantom was placed in an elevated head holder to avoid minor motion, and was rotated by $45^{\circ}$ so that the ESF calculation at the top of the image could be carried out without passing through the hole 
which is used to place the ionization chamber when measuring radiation dose. If rotation was not performed, the trajectory from the center to the top of the image would not be homogeneous, and MTF calculations would not be accurately measured.

The two phantoms were scanned by the Philips Brilliance CT 16-Slice. The setting specifications are tabulated in Table 1 . The various reconstruction kernel characteristics are indicated in Table 2.

TABLE I

\begin{tabular}{|l|l|}
\hline CT settings \\
\hline Setting specification & Value \\
\hline Tube voltage & $120 \mathrm{kVp}$ \\
\hline Exposure & $300 \mathrm{mAs}$ \\
\hline Slice thickness & $2 \mathrm{~mm}$ \\
\hline FOV & $20 \mathrm{~cm}$ \\
\hline Scan option & Helical \\
\hline Pitch & 0.56 \\
\hline Rotation time & $0.75 \mathrm{~s}$ \\
\hline
\end{tabular}

TABLE II

Reconstruction kernel code and characteristics

\begin{tabular}{|l|l|}
\hline Kernel code name & Characteristic \\
\hline A & $\begin{array}{l}\text { Smoothing filter, used to render } \\
\text { images of soft tissues. }\end{array}$ \\
\hline B & $\begin{array}{l}\text { Smoothing, but sharper and } \\
\text { noisier than A }\end{array}$ \\
\hline C & $\begin{array}{l}\text { Sharp filter, creating relatively } \\
\text { low-noise images in head scans. }\end{array}$ \\
\hline D & $\begin{array}{l}\text { Sharp, edge-enhancing filter, } \\
\text { creating relatively high-noise } \\
\text { images. }\end{array}$ \\
\hline UA & $\begin{array}{l}\text { Sharper, used for image quality } \\
\text { tests. }\end{array}$ \\
\hline $\begin{array}{l}\text { Designed for head scans only. } \\
\text { Minimizes the beam-hardening } \\
\text { artifacts and significantly } \\
\text { improves the bone-soft tissue } \\
\text { interface (in areas such as brain }\end{array}$ \\
\hline
\end{tabular}

\begin{tabular}{|l|l|}
\hline UB & or orbits). \\
\hline UC & $\begin{array}{l}\text { Designed to detect small lesions } \\
\text { with improved bone/soft tissue } \\
\text { interface (in areas such as brain } \\
\text { or orbits) Allows good } \\
\text { detectability of low contrast at } \\
\text { moderate resolution. }\end{array}$ \\
\hline YC & $\begin{array}{l}\text { Designed to detect small lesions } \\
\text { with improved bone/soft tissue } \\
\text { interface (in areas such as brain } \\
\text { or orbits). Increases noise in } \\
\text { images. }\end{array}$ \\
\hline YD & $\begin{array}{l}\text { Sharp and noisy. Recommended } \\
\text { for reconstruction of lungs, } \\
\text { sinuses, facial bones, dental, and } \\
\text { orthopedics. }\end{array}$ \\
\hline $\begin{array}{l}\text { Extremely sharp and noisy. } \\
\text { Recommended for } \\
\text { reconstruction of IAC (when } \\
\text { scan is HR rather than UHR) and } \\
\text { sinuses. Also for reconstruction } \\
\text { of lungs and orthopedics. }\end{array}$ \\
\hline
\end{tabular}

The images were in the Digital Imaging and Communication in Medicine (DICOM) format [35]. The images were processed using MATLAB software, on a laptop with The an Intel (R) Core (TM) type i55200U CPU @ 2.20GHZ.

\section{B. Methods of MTF measurements \\ Point phantom}

The phantom had a copper wire section that produces a point in the image. We manually drew the ROI with an area on the ROI of 20 pixels $\times 20$ pixels as shown in Fig. 1(a). We used a method previously introduced by Anam et al. [25] to calculate the MTF. The LSF calculations require the value of $\mathrm{S}(\mathrm{x})$ as sampling data information:

$$
S(x)=\sum_{y \min }^{y \max } R O I(x, y)
$$


where $\mathrm{ROI}(\mathrm{x}, \mathrm{y})$ is the area for measuring MTF. After the sampling data is obtained, the $S(x)$ was differentiated into $\mathrm{S}^{\prime}(\mathrm{x})$. The LSF was normalized with the following equation:

$$
\operatorname{LSF}(x)=\frac{S^{\prime}(x)}{\sum_{x \min }^{x \max } S^{\prime}(x)}
$$

where $x$ min and xmax are pixel position from minimum to maximum in coordinate " $x$ ". LSF was zeroed and then Fourier transformed to give the MTF:

$$
\operatorname{MTF}(k)=\mid F(\operatorname{zeroed} \operatorname{LSF}(x) \mid
$$

where $\mathrm{F}$ is the Fourier transformation and $\mathrm{k}$ is the spatial resolution using the point object method.

The MTF measurements were performed on 30 slices of the image. An example of results of the MTF calculation using automated edge contouring for the "A" kernel for one slice is shown in Fig. 1(b).
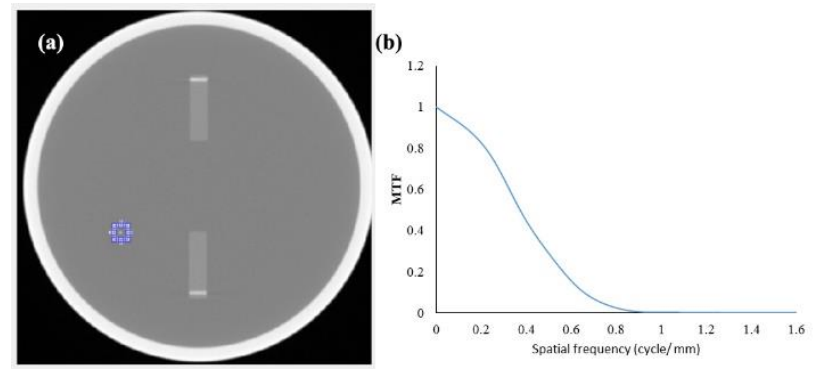

Fig. 1. (a) Manual shaped ROI on the vendor's phantom for kernel type A for MTF measurement using the point method. (b) The measured MTF on one slice using the " $\mathrm{A}$ " kernel.

\section{Small circular phantom}

We also measured the MTF using the edge of the small circular (S-circular) teflon object utilizing the ImQuest software developed by Samei et al. [26] The manual ROI for the type " $\mathrm{A}$ " reconstruction kernel is shown in Fig. 2(a). The result of the MTF calculation is shown in Fig. 2(b). In this paper, we refer to this method as "S-circular".
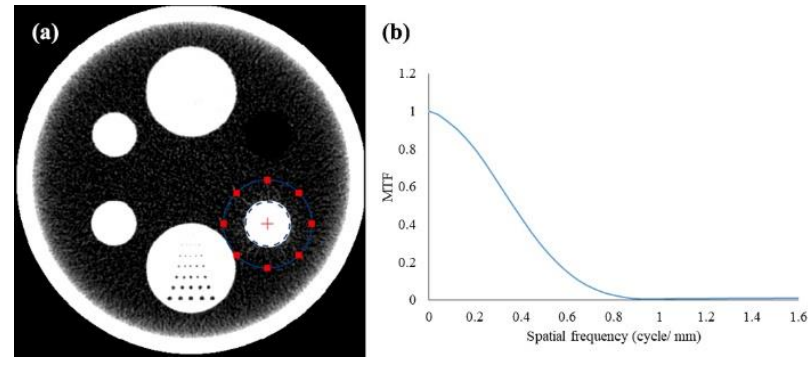

Fig. 2. (a) Manual circular ROI to calculate MTF for reconstruction kernel type "A" using the ImQuest

software. (b) The result of MTF calculation.

\section{PMMA phantom}

The algorithm for automated MTF calculation on the PMMA phantom was developed by Anam et al. [30] The algorithm automatically contoured the edges of the phantom image, and determined the centroid of the image [36]. After determining the location of the centroid, the algorithm draws a line towards the top of the image. The intersection of this line with the contoured edge is taken as the center of a ROI, as shown in Fig. 3(a), which is used to calculate the ESF (Fig. 3(b)).

The ESF was differentiated to give the LSF (Fig. 3(c)), which was subsequently converted to the MTF using the Fourier transformation. The discrete Fourier transform from the LSF to the MTF is given by:

$$
\operatorname{MTF}(k)=\sum_{j=0}^{N-1} x(j) e^{(-i 2 \pi k j) / N}
$$

where $\mathrm{N}$ is the vector length of the LSF. The equation for calculating the spatial frequency of the MTF is given by:

$$
k=\frac{1}{N \times \frac{F O V}{512}}
$$

We used 25 slices of the image for every variation of reconstruction kernel. The resulting MTF using automated edge contouring for the " $\mathrm{A}$ " type kernel is shown in Fig. 3(d). 

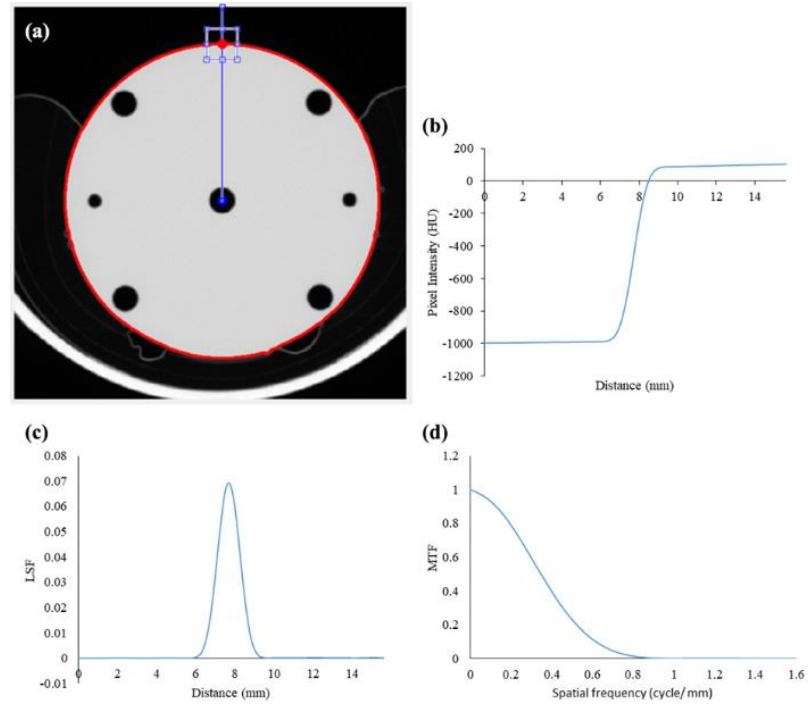

Fig. 3. (a) ROI for automated MTF calculation on the edge of PMMA phantom. The center of the ROI is set at the crossing between the automated edge and the straight line from the centroid towards the edge of the image. (b) The ESF was used to derive the (c) LSF, and the LSF was Fourier transformed to obtain (d) the MTF.

\section{RESULTS}

\section{A. Point phantom}

The result of MTFs calculation using the point method are shown in Fig. 4 . The $10 \%$ and 50\% MTFs measured on the point phantom for various reconstruction kernels are tabulated in Table 3. The reconstruction kernel "UA" produced the lowest spatial resolution (the $10 \%$ and $50 \%$ MTFs were 0.57 and 0.32 cycle $/ \mathrm{mm}$, respectively). The highest spatial resolution value for $10 \%$ MTF was obtained with reconstruction kernel kernel "YC" (1.10 cycles/mm), and for $50 \%$ MTF was obtained with reconstruction kernel "YD" (0.78 cycles/mm).

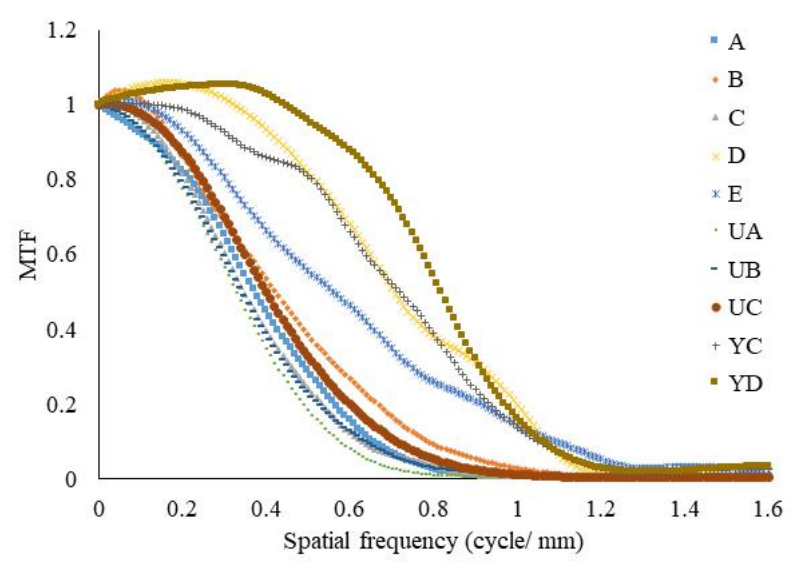

Fig. 4. MTFs using the point method for various reconstruction kernels.

TABLE III

$10 \%$ and $50 \%$ MTFs using the point method for various reconstruction kernels.

\begin{tabular}{|l|l|l|}
\hline $\begin{array}{l}\text { Reconstruction } \\
\text { kernel }\end{array}$ & $\begin{array}{l}10 \% \quad \text { MTF } \\
\text { (cycle/mm) }\end{array}$ & $\begin{array}{l}\mathbf{5 0 \%} \text { MTF } \\
\text { (cycle/mm) }\end{array}$ \\
\hline A & 0.65 & 0.37 \\
\hline B & 0.78 & 0.42 \\
\hline C & 0.62 & 0.34 \\
\hline D & 1.06 & 0.73 \\
\hline E & 1.06 & 0.55 \\
\hline UA & 0.57 & 0.32 \\
\hline UB & 0.63 & 0.34 \\
\hline UC & 0.70 & 0.39 \\
\hline YC & 1.10 & 0.70 \\
\hline YD & 1.03 & 0.78 \\
\hline
\end{tabular}

\section{B. S-circular phantom}

The result of MTF calculation using the ImQuest software on the edge of the Teflon circular object is shown in Fig. 5. The $10 \%$ and 50\% MTFs measured by this method are tabulated in Table 4 . As with the previous method, reconstruction kernel "UA" produced the lowest spatial resolution. The $10 \%$ and $50 \%$ MTSs were 0.57 and 0.33 cycles $/ \mathrm{mm}$, respectively. The highest $10 \%$ MTF was obtained with reconstruction kernel "D" and "E" (1.09 cycles $/ \mathrm{mm}$ ), and the highest $50 \%$ MTF was achieved with the "D" and "YD" filters (0.76 cycles/mm). 


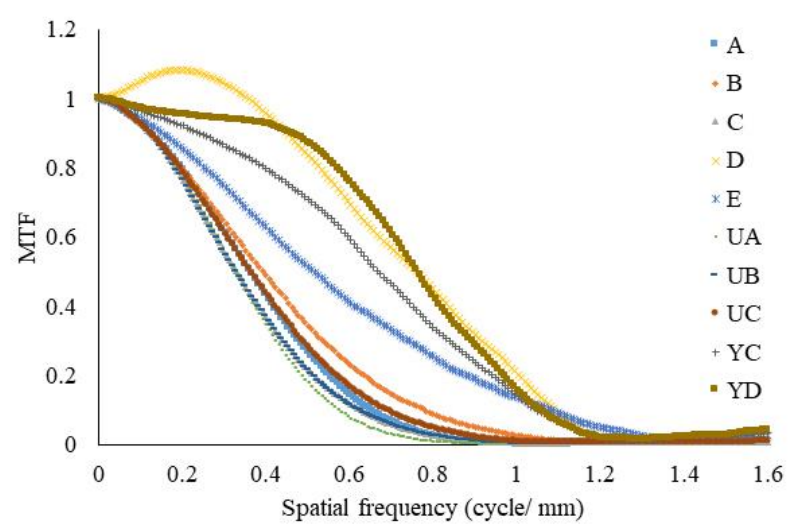

Fig. 5. MTFs using the small-circular Teflon object for various reconstruction kernels.

TABLE IV

$10 \%$ and $50 \%$ MTFs using the small-circular Teflon for various reconstruction kernels.

\begin{tabular}{|l|l|l|}
\hline $\begin{array}{l}\text { Reconstruction } \\
\text { kernel }\end{array}$ & $\begin{array}{l}10 \% \quad \text { MTF } \\
\text { (cycle/mm) }\end{array}$ & $\begin{array}{l}\text { 50\% MTF } \\
\text { (cycle/mm) }\end{array}$ \\
\hline A & 0.65 & 0.36 \\
\hline B & 0.78 & 0.39 \\
\hline C & 0.63 & 0.33 \\
\hline D & 1.09 & 0.76 \\
\hline E & 1.09 & 0.51 \\
\hline UA & 0.57 & 0.33 \\
\hline UB & 0.63 & 0.33 \\
\hline UC & 0.69 & 0.36 \\
\hline YC & 1.05 & 0.67 \\
\hline YD & 1.06 & 0.76 \\
\hline
\end{tabular}

\section{PMMA phantom}

Fig. 6. shows the MTFs for various reconstruction kernels using the automated edge of a PMMA phantom. The $10 \%$ and $50 \%$ MTFs for various reconstruction kernels are tabulated in Table 5. The reconstruction kernel "UA" produced the lowest spatial resolution, with $10 \%$ and $50 \%$ MTF of 0.54 and 0.31 cycles $/ \mathrm{mm}$ respectively. The highest $10 \%$ MTF was obtained with the reconstruction kernel " $D$ " (1.03 cycles $/ \mathrm{mm}$ ), and the highest 50\% MTF was achieved with the reconstruction kernel "YD" (0.67 cycles/mm).

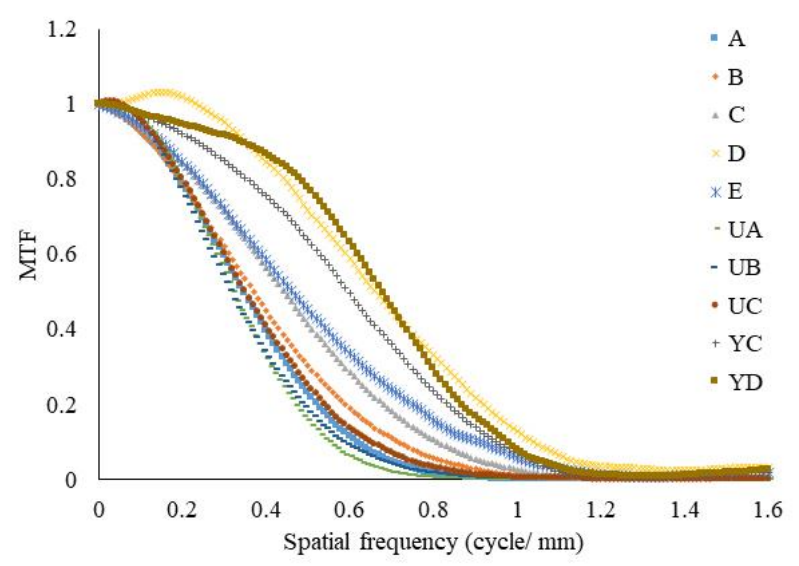

Fig. 6. MTFs using the PMMA for various reconstruction kernels.

\section{TABLE V}

$10 \%$ and $50 \%$ MTFs using the PMMA automated edge contouring method for various reconstruction kernels.

\begin{tabular}{|l|l|l|}
\hline $\begin{array}{l}\text { Reconstruction } \\
\text { kernel }\end{array}$ & $\begin{array}{l}10 \% \quad \text { MTF } \\
\text { (cycle/mm) }\end{array}$ & $\begin{array}{l}50 \% \quad \text { MTF } \\
\text { (cycle/mm) }\end{array}$ \\
\hline A & 0.61 & 0.34 \\
\hline B & 0.71 & 0.36 \\
\hline C & 0.81 & 0.44 \\
\hline D & 1.03 & 0.66 \\
\hline E & 0.91 & 0.46 \\
\hline UA & 0.54 & 0.31 \\
\hline UB & 0.58 & 0.32 \\
\hline UC & 0.64 & 0.35 \\
\hline YC & 0.94 & 0.59 \\
\hline YD & 0.97 & 0.67 \\
\hline
\end{tabular}

\section{Comparison of MTF measurements using various methods}

The MTFs from the three methods for the four kernels, "A", "D", "UA", and "YD", are shown in Figure 7. Type "A" and "UA" produced low spatial resolution values, while type " $D$ " and "YD" produced higher values on each method. Fig. 7(a) and Fig. 7(c) show that "A" and "UA" produced almost identical results, while Fig. 7(b) and Fig. 7(d) show that " $D$ " and "YD" produced different MTFs depending on which method was used. 

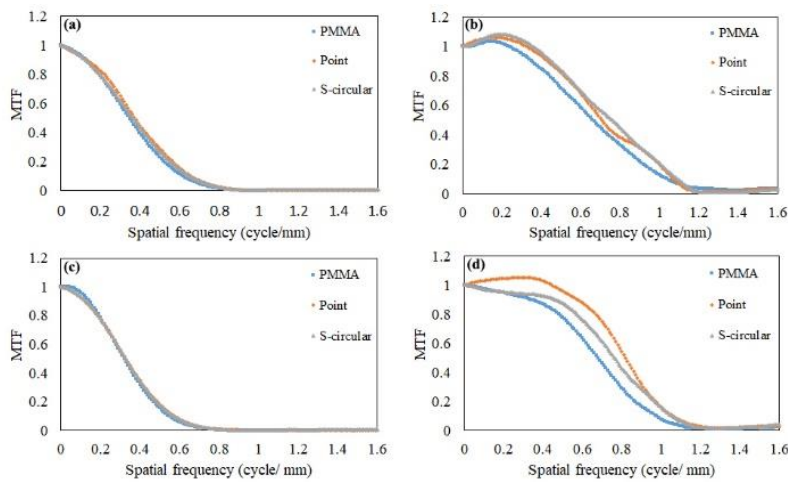

Fig. 7. Comparison of MTFs from the point, S-circular, and edge PMMA methods for four kernel filters: (a) “A”, (b) "D”, (c) "UA", and (d) "YD".

\section{E. Discussion}

The purpose of this study was to compare the MTF measurement methods using the point object, Scircular object, and automated edge of PMMA phantom for various reconstruction kernels. Different reconstruction kernels produced different MTFs. The "UA" kernel had the lowest spatial resolution value and the "YD" kernel had the highest spatial resolution, for all measurement methods. The "UA" kernel was designed to minimize hardening artifacts to produces in a smooth image and less noise. While the "YD" kernel was designed as an extremely sharp kernel that produces sharp images with high noise.

We found that all three methods produce fairly comparable MTFs for all kernels used. However, the automated edge of PMMA produced slightly smaller spatial resolution values compared with the two other methods. This is due to the linear averaging used on the curved edge in the PMMA method [30]. This can be overcome by using a radial ROI or by a presampled method, i.e. shifting and rebinning along the curvature of the edge of the phantom. However, the differences between automated edge of PMMA and point phantoms were very small, i.e. 0.04, 0.07, 0.19, $0.03,0.15,0.03,0.05,0.06,0.16$, and 0.06 cycle/ $\mathrm{mm}$ at $10 \% \mathrm{MTF}$ and $0.03,0.06,0.1,0.07,0.09,0.01,0.02$, $0.04,0.11$, and 0.11 cycle/ $\mathrm{mm}$ at $50 \% \mathrm{MTF}$ for reconstruction filter types of "A", "B", "C", "D", " $E$ ", "UA", "UB”, "UC", "YC", "YD”, respectively. On average the differences were 0.04 cycle/mm for $10 \%$ MTF and 50\% MTF respectively. The differences between the automated edge of PMMA and the Scircular phantom were also very small, i.e. 0.04, 0.07, $0.18,0.06,0.18,0.03,0.05,0.05,0.11$, and 0.09 cycle/ $\mathrm{mm}$ at $10 \% \mathrm{MTF}$ and $0.02,0.03,0.11,0.1,0.05,0.02$, $0.01,0.01,0.08$, and 0.09 cycle/ $\mathrm{mm}$ at $50 \% \mathrm{MTF}$ for reconstruction kernel types of “A”, "B”, “C”, “D”, “E”, "UA", "UB", "UC", "YC", "YD". On average the differences were 0.05 cycle/mm and 0.03 cycle/mm for $10 \% \mathrm{MTF}$ and $50 \% \mathrm{MTF}$. Based on this finding, the edge PMMA is able to accurately measure MTF as long as the Nyquist theorem is not violated.

The point method produces more variable MTF curves due to noise within the ROI. The method is simple for calculating the MTF, but the ROI is determined manually by the user. The S-circular phantom also produces a slightly elevated spatial resolution value with a variable MTF curve. The placement of the ROI in this method is also manually determined by the user. Conversely the edge PMMA method has a more stable MTF because it is less dependent on noise. The method is automatically determined, so that it is more convenient to implement in a busy clinical setting.

Our comparison showed that each method has its own advantages and disadvantages. The results of all three methods are comparable, with the point phantom and S-circular phantom giving almost identical results.

\section{CONCLUSION}

We have compared the methods of MTF calculations using a point object, an S-circular Teflon object and the automated edge of a PMMA phantom for various reconstruction kernels. We found that all methods produce similar MTF results, although each method has its own specific characteristics. The point method tends to produce a variable MTF because it is 
influenced by noise in the image, the PMMA phantom edge method produces a smaller MTF especially when it approaches the Nyquist frequency, and the S-circular using ImQuest produces a more consistent MTF. All methods were able to differentiate among all the kernels used.

\section{ACKNOWLEDGMENT}

This work was funded by the World Class Research University (WCRU), Diponegoro University, No. 11808/UN7.6.1/PP/2021.

\section{REFERENCES}

[1]. Camera L, Pezzullo F, Acampora A, et al. Multidetector CT enterography in active inflammatory bowel disease: Image quality and diagnostic efficacy of a low-radiation high contrast protocol. Clin Imaging. 2019;58(May):27-33.

doi:10.1016/j.clinimag.2019.06.007

[2]. Watanabe H, Honda E, Tetsumura A, Kurabayashi T. A comparative study for spatial resolution and subjective image characteristics of a multi-slice CT and a cone-beam CT for dental use. Eur J Radiol. 2011;77(3):397-402. doi:10.1016/j.ejrad.2009.09.023

[3]. Ding Y, Richter A, Stiller W, Kauczor HU, Weber TF. Association between true noncontrast and virtual non-contrast vertebral bone CT attenuation values determined using duallayer spectral detector CT. Eur J Radiol. 2019;121(November):108740. doi:10.1016/j.ejrad.2019.108740

[4]. Ohkubo M, Wada S, Kayugawa A, Matsumoto $\mathrm{T}$, Murao K. Image filtering as an alternative to the application of a different reconstruction kernel in CT imaging: Feasibility study in lung cancer screening. Med Phys. 2011;38(7):39153923. doi:10.1118/1.3590363
[5]. Talha SMU, Mairaj T, Yousuf W Bin. Novel FBP based sparse-view CT reconstruction scheme using self-shaping spatial filter based morphological operations and scaled reprojections. Biomed Signal Process Control. 2021;64(November 2020):102323. doi:10.1016/j.bspc.2020.102323

[6]. Gierada DS, Bierhals AJ, Choong CK, et al. Effects of CT Section Thickness and Reconstruction Kernel on Emphysema Quantification. Relationship to the Magnitude of the CT Emphysema Index. Acad Radiol. 2010;17(2):146-156.

doi:10.1016/j.acra.2009.08.007

[7]. Yoo WJ, Lim YS, Ahn KJ, Choi BG, Kim JY, Kim SH. Assessment of vertebral artery stents using 16-slice multi-detector row CT angiography in vivo evaluation: Comparison of a medium-smooth kernel and a sharp kernel. Eur J Radiol. 2009;70(2):362-368. doi:10.1016/j.ejrad.2008.01.039

[8]. Paul J, Krauss B, Banckwitz R, Maentele W, Bauer RW, Vogl TJ. Relationships of clinical protocols and reconstruction kernels with image quality and radiation dose in a 128-slice CT scanner: Study with an anthropomorphic and water phantom. Eur J Radiol. 2012;81(5):e699-e703.

doi:10.1016/j.ejrad.2011.01.078

[9]. Achenbach S, Boehmer K, Pflederer T, et al. Influence of slice thickness and reconstruction kernel on the computed tomographic attenuation of coronary atherosclerotic plaque. J Cardiovasc Comput Tomogr. 2010;4(2):110-115. doi:10.1016/j.jcct.2010.01.013

[10]. Davis AT, Palmer AL, Pani S, Nisbet A. Assessment of the variation in CT scanner performance (image quality and Hounsfield units) with scan parameters, for image optimisation in radiotherapy treatment planning. Phys Medica. 2018;45(November 2017):198-204. doi:10.1016/j.ejmp.2017.11.036 
[11]. Yang Y, Wu YC, Li L, et al. Design and characterization of high energy micro-CT with a laser-based X-ray source. Results Phys. 2019;14(August 2018):102382. doi:10.1016/j.rinp.2019.102382

[12]. Wu RY, Williamson TD, Sahoo $\mathrm{N}$, et al. Evaluation of the high definition field of view option of a large-bore computed tomography scanner for radiation therapy simulation. Phys Imaging Radiat Oncol. 2020;13(July 2019):4449. doi:10.1016/j.phro.2020.03.004

[13]. Vergalasova I, McKenna M, Yue NJ, Reyhan M. Impact of computed tomography (CT) reconstruction kernels on radiotherapy dose calculation. J Appl Clin Med Phys. 2020;21(9):178-186. doi:10.1002/acm2.12994

[14]. Jia MX, Zhang X, Li N, Han CB. Impact of different CBCT imaging monitor units, reconstruction slice thicknesses, and planning CT slice thicknesses on the positioning accuracy of a MV-CBCT system in head-and-neck patients. J Appl Clin Med Phys. 2012;13(5):117125. doi:10.1120/jacmp.v13i5.3766

[15]. Carew RM, Viner MD, Conlogue G, MárquezGrant N, Beckett S. Accuracy of computed radiography in osteometry: A comparison of digital imaging techniques and the effect of magnification. J Forensic Radiol Imaging. 2019;19(October). doi:10.1016/j.jofri.2019.100348

[16]. Kayugawa A, Ohkubo M, Wada S. Accurate determination of ct point-spread-function with high precision. J Appl Clin Med Phys. 2013;14(4):216-226.

doi:10.1120/jacmp.v14i4.3905

[17]. Kappadath SC. Effects of voxel size and iterative reconstruction parameters on the spatial resolution of $99 \mathrm{mTc}$ SPECT/CT. J Appl Clin Med Phys. 2011;12(4):210-220. doi:10.1120/jacmp.v12i4.3459

[18]. Gayou O. Influence of acquisition parameters on MV-CBCT image quality. J Appl Clin Med
Phys. 2012;13(1):14-26. doi:10.1120/jacmp.v13i1.3638

[19]. Mikš A, Pokorný P. Edge spread function of Talbot phenomenon. Optik (Stuttg). 2016;127(19):8065-8069.

doi:10.1016/j.ijleo.2016.06.003

[20]. Saiga R, Takeuchi A, Uesugi K, Terada Y, Suzuki Y, Mizutani R. Method for estimating modulation transfer function from sample images. Micron. 2018;105(November 2017):6469. doi:10.1016/j.micron.2017.11.009

[21]. Suljic A, Tomse P, Jensterle L, Skrk D. The impact of reconstruction algorithms and time of flight information on PET/CT image quality. Radiol Oncol. 2015;49(3):227-233. doi:10.1515/raon-2015-0014

[22]. Goodenough D, Levy J, Olafsdottir H, Olafsson I. Design and development of a phantom for tomosynthesis with potential for automated analysis via the cloud. J Appl Clin Med Phys. 2018;19(3):291-300. doi:10.1002/acm2.12297

[23]. Renner WD, Norton K, Holmes T. A method for deconvolution of integrated electronic portal images to obtain incident fluence for dose reconstruction. J Appl Clin Med Phys. 2005;6(4):22-39. doi:10.1120/jacmp.v6i4.2104

[24]. Ohno K, Ohkubo M, Marasinghe JC, Murao K, Matsumoto T, Wada S. Accuracy of lung nodule density on HRCT: Analysis by PSF-based image simulation. J Appl Clin Med Phys. 2012;13(6):277-292. doi:10.1120/jacmp.v13i6.3868

[25]. Anam C, Fujibuchi T, Haryanto F, et al. Automated MTF measurement in CT images with a simple wire phantom. Polish J Med Phys Eng. 2019;25(3):179-187. doi:10.2478/pjmpe2019-0024

[26]. Samei E, Bakalyar D, Boedeker KL, et al. AAPM 233. Performance Evaluation of Computed Tomography Systems.; 2019.

[27]. Richard S, Husarik DB, Yadava G, Murphy SN, Samei E. Towards task-based assessment of CT 
performance: System and object MTF across different reconstruction algorithms. Med Phys. 2012;39(7):4115-4122.

doi:10.1016/j.ejmp.2016.07.203

[28]. Kawashima H, Ichikawa K, Matsubara K, Nagata H, Takata T, Kobayashi S. Quality evaluation of image-based iterative reconstruction for CT: Comparison with hybrid iterative reconstruction. J Appl Clin Med Phys. 2019;20(6):199-205. doi:10.1002/acm2.12597

[29]. Ichikawa K, Kawashima H, Shimada M, Adachi T, Takata T. A three-dimensional crossdirectional bilateral filter for edge-preserving noise reduction of low-dose computed tomography images. Comput Biol Med. 2019;111(May):103353.

doi:10.1016/j.compbiomed.2019.103353

[30]. Anam C, Fujibuchi T, Budi WS, Haryanto F, Dougherty G. An algorithm for automated modulation transfer function measurement using an edge of a PMMA phantom: Impact of field of view on spatial resolution of CT images. J Appl Clin Med Phys. 2018;19(6):244-252. doi:10.1002/acm2.12476

[31]. Zabilal Hak E, Anam C, Setia Budi W, Dougherty G. An improvement in automatic MTF measurement in CT images using an edge of the PMMA phantom. J Phys Conf Ser. 2020;1505(1). doi:10.1088/17426596/1505/1/012039

[32]. Philips. Instruction for Use Brilliance CT (Vol. 1). Cleveland, Ohio: Philips Healthcare (Cleveland), Inc.; 2010.

[33]. Sommerville M, Poirier Y, Tambasco M. A measurement-based $\mathrm{X}$-ray source model characterization for CT dosimetry computations. J Appl Clin Med Phys. 2015;16(6):386-400. doi:10.1120/jacmp.v16i6.5231

[34]. Kron T, Donahoo G, Lonski P, Wheeler G. A technique for total skin electron therapy (TSET) of an anesthetized pediatric patient. J Appl Clin
Med Phys. 2018;19(6):109-116. doi:10.1002/acm2.12457

[35]. Boos J, Lanzman RS, Meineke A, et al. Dose monitoring using the DICOM structured report: Assessment of the relationship between cumulative radiation exposure and BMI in abdominal CT. Clin Radiol. 2015;70(2):176-182. doi:10.1016/j.crad.2014.11.002

[36]. Zhao Z, Hui M, Liu M, Dong L, Kong L, Zhao Y. Centroids computation and point spread function analysis for reverse Hartmann test. Opt Commun. 2017;387(October 2016):328-337. doi:10.1016/j.optcom.2016.11.063

\section{Cite this article as :}

Fakhri Ramadhani Arisyi, Choirul Anam, Catur Edi Widodo, "Comparison of MTF Measurement Methods in CT Images for Various Reconstruction Kernels", International Journal of Scientific Research in Science and Technology (IJSRST), Online ISSN : 2395-602X, Print ISSN : 2395-6011, Volume 8 Issue 3, pp. 396-405, May-June 2021. Available at doi : https://doi.org/10.32628/IJSRST218333

Journal URL : https://ijsrst.com/IJSRST218333 